\title{
New "sutureless" technique of ileostomy and colostomy
}

\author{
M. V. Phadke $\cdot$ L. H. Stocks $\cdot$ Y. G. Phadke
}

Published online: 11 July 2007

(C) Springer Science+Business Media, LLC 2007

\section{Erratum to: Surg Endosc}

DOI 10.1007/s00464-007-9194-z

Affiliations for the authors' L. H. Stocks and Y. G. Phadke were published incorrectly. The affiliation is now corrected. Springer regrets the error.

The online version of the original article can be found under doi:10.1007/s00464-007-9194-Z

M. V. Phadke $(\square)$

Surgery, Retired, WakeMed Affiliated with UNCCH, Raleigh, NC, USA

e-mail: phadkemadhav@hotmail.com

L. H. Stocks

Rex Hospital (affiliated with UNC Chapel Hill, NC), Raleigh, NC, USA

Y. G. Phadke

Indiana Hospital, Indiana, PA, USA 